\title{
Effects of land use on fish assemblages in Patagonian low order streams
}

\author{
Cecilia Yanina Di Prinzio ${ }^{1,2 *}$, Ricardo Jorge Casaux ${ }^{1,2,3}$ and María Laura Miserendino ${ }^{1,2}$ \\ 1 Consejo Nacional de Investigaciones Científicas y Técnicas (CONICET), Av. Rivadavia 1917, 1033 Buenos Aires, Argentina \\ ${ }^{2}$ Laboratorio de Investigaciones en Ecología y Sistemática Animal (LIESA), Universidad Nacional de la Patagonia, Ruta 259 km. 5 , \\ Planta de Aromáticas, 9200 Esquel, Chubut, Argentina \\ 3 Instituto Antártico Argentino, Cerrito 1248, 1010 Buenos Aires, Argentina
}

Received 26 August 2009; Accepted 27 October 2009

\begin{abstract}
We assessed the effects of land use on the structure of stream fish assemblages in Northwest Patagonia, Argentina. To this end, a total of 18 sites distributed in 15 streams were sampled during the low water period. At each site, 26 regional and local scale variables were used to describe the environmental conditions. The macroinvertebrate density, and the composition and abundance of fish were then recorded. Statistical associations between local assemblage structures and environmental variables were quantified by canonical correspondence analyses. The results revealed that, at a regional scale, the fish assemblages were primarily determined by watershed features like altitude and catchment area, and by land use effects (exotic forest and pasture). Assemblage compositions were also related to some local-scale features such as water velocity, food availability (density of benthic macroinvertebrates), instream characteristic and riparian features. Also, the observed fish species richness was low. Overall, exotic salmonids largely dominated in the samples both in numbers of individuals $(98.9 \%)$ and in biomass $(99.9 \%)$, whereas native fish (Hatcheria macraei and Odontesthes hatcheri) were scarcely represented. Rainbow trout (Oncorhynchus mykiss) was the most abundant fish, and was present in all streams. Native species were restricted to five streams located in the ecotone between the Andes and the steppe, where salmonids were also present. Salmonids were the only fish at Andean streams which suggest the existence of a strong geographic segregation between native and exotic species. Some aspects related to the incidence of the introduced species in the structure of fish assemblages are discussed.
\end{abstract}

Key words: Fish assemblages / land use effects / northwest Patagonia

\section{Introduction}

Fish are frequently the focus of stream studies since they have economical value and, in relatively undisturbed environments, they can be good indicators of stream and watershed conditions (Moyle et al., 2003). The understanding of the relationships among landscape, stream characteristics and fish assemblages has thus motivated several studies (e.g. Poff, 1997; Porter et al., 2000; Higgins and Strauss, 2008). Some of these studies indicated that fish assemblages can be structured not only by local processes, but also by large-scale environmental factors (Magalhães et al., 2002; Hoeinghaus et al., 2006). Thus, to understand the fish species-habitat relationships multiscale approaches are necessary (Ferreira et al., 2007).

\footnotetext{
*Corresponding author: cdiprinzio@liesa.org.ar
}

Different human activities affect stream characteristics, and then fish assemblages. Kolar and Lodge (2000) mentioned that the introduction of non indigenous fish species comprise the first or second most important anthropogenic impact on freshwater ecosystems. Most introduced species can cause a perceptible environmental impact, which is usually impossible to undo. Some of the potential impacts of introduced fish species include introduction of diseases or parasites, trophic alterations, hybridization, decrease of native fish populations (Allan, 1995).

Besides the introduction of non indigenous fish species, forestry practices (which results in the increase of sediment and nutrient inputs, discharge, and water temperature, see Wallace et al., 1997) can also affect the structure and function of the stream biota including invertebrates and fishes (Rowe et al., 2002). Conversion of native forest into pastures as a consequence of land use for agriculture has 
produced a wide-scale degradation of aquatic ecosystems in several countries (Heartsill-Scalley and Aide, 2003; Gerhard et al., 2004; Lorion and Kennedy, 2009). This land use practice affects freshwater systems by increasing the runoff of silt, fertilizers, and pesticides, whereas removal of large volumes of water for irrigation often reduces habitat availability, and increases salinity. Urban activities also negatively affect the water quality and their effects are particularly severe in localities downstream the city sewage discharge (Pesce and Wunderlin, 2000). Among the main negative effects we can mention: alteration of the ecosystem functioning, reduction of the biological uniqueness of the ecosystem, alteration of the biodiversity at a variety of spatial scales and changes in the distribution and movements of fishes (Boët et al., 1994).

Although all of the human activities described above are well established in Patagonia, their current or potential effects on streams and fish communities were scarcely considered in previous studies (see Pascual et al., 2007). As a consequence, the relationship between stream habitat integrity and native species health is still poorly understood. Thus, the aims of this paper are (1) to describe the spatial variability of the structure of stream fish communities in the northwest of Chubut, Patagonia, Argentina, and (2) to identify the land use effects that influence and determine the structure of fish assemblages.

\section{Material and methods}

\section{Study area}

This study was conducted during March 2006 in the Chubut Province, Argentina. The study area (41 ${ }^{\circ} 59^{\prime}$ to $43^{\circ} 44^{\prime} \mathrm{S}$ and $71^{\circ} 17^{\prime}$ to $71^{\circ} 33^{\prime} \mathrm{W}$ ) is located in the AndeanHumid and the Sub-Andean Sub-humid biozones. The climate is cool-temperate. There is a strong west-east rainfall gradient with most of the rainfall concentrated between May and September. River discharge is bimodal and determined by rainfall, which occurs mainly in winter and by the snowmelt in spring.

The Northwest of the Chubut province is characterized by the Subantartic Forest which is dominated by perennial (Austrocedrus chilensis, Nothofagus dombeyi and Maytenus boaria) and deciduous ( $N$. pumilio, $N$. antarctica) species (Fig. 1). Some ecotone watercourses as piedmont rivers are mainly flanked by Salix fragilis and S. nigra.

\section{Fish fauna of Patagonia}

The Patagonian ichthyofauna belongs to the Austral biogeographic region and presents a low species richness (Ringuelet, 1975). The native fish fauna comprise only 15 species (Baigún and Ferriz, 2003), the naked characin (Gymnocharacinus bergii) being the only threatened species in the region (Ortubay and Cussac, 2000). Prior to introduction of trout, most native species were surely much more widespread and abundant than nowadays.
There are some evidences that introduced rainbow trout prey heavily on native fishes (McDowall, 2003; Arismendi et al., 2009; among others). In this way, it appears that Diplomystidae and Trichomycteridae, qualified as catfish "living fossils", had a wider distribution in the past. Thus, their current restricted distribution could result from a variety of pressures like habitat loss, predation and competition with salmonids. The rest of the native species are actually quite widespread, being found in most major rivers (Pascual et al., 2007). Less is known about the situation of native fish in low order stream.

Since 1904, thirteen salmonids species were introduced in Patagonia (Pascual et al., 2002). Currently, the most widely distributed species are Oncorhynchus mykiss, Salmo trutta and Salvelinus fontinalis. Recently, the anadromous Chinook salmon Oncorhynchus tshawytscha was observed spawning in headwaters of Pacific and Atlantic basins in Argentina (Di Prinzio and Pascual, 2008).

\section{Site selection}

The study was carried out during the low water period (March 2006) at 18 sampling sites located in 15 streams (Fig. 1). We chose this month because most streams have stable flow conditions (Coronato and del Valle, 1988). Five different land uses (identified as potential sources of environmental disturbance) were considered: urban (sites located in or downstream urbanizations), pasture (with extensive livestock), exotic forest, and native forest. Urban sites corresponded to the towns Esquel (30977 inhabitants), Cholila (2190 inhabitants) and Corcovado (1848 inhabitants). Additionally, as a reference site for urban sites, three pre-urban sampling sites (located upstream close to urbanization) were also considered. Three sampling sites (or replicates) corresponding to each type of land use were sampled (Table 1). Sampling site selection was primarily determined by the dominance of the land uses indicated above $2000 \mathrm{~m}$ upstream reach with a $150 \mathrm{~m}$ lateral buffer. However, the accessibility to streams, the topography, road conditions and the presence of wadeable areas also influenced the selection of the sites.

\section{Data collection}

The stream segments considered for fish sampling were 90-100 m long. Sampling protocol, logistic constraints and site-specific characteristics were considered in establishing the length of each section to be sampled. The width of the sampling area was coincident with the stream width, except in those sections of the streams presenting nonwadeable sites with swift currents. Considering the length and width of the sampling area we estimated the area really sampled. Thus, for each stream the density and biomass of fish is expressed as number of individuals (individuals. $\mathrm{m}^{-2}$ ) and biomass $\left(\mathrm{g} . \mathrm{m}^{-2}\right)$ per area sampled. Fish communities were sampled by electro-fishing with a battery powered backpack machine (output $300 \mathrm{~W}$ ) set 


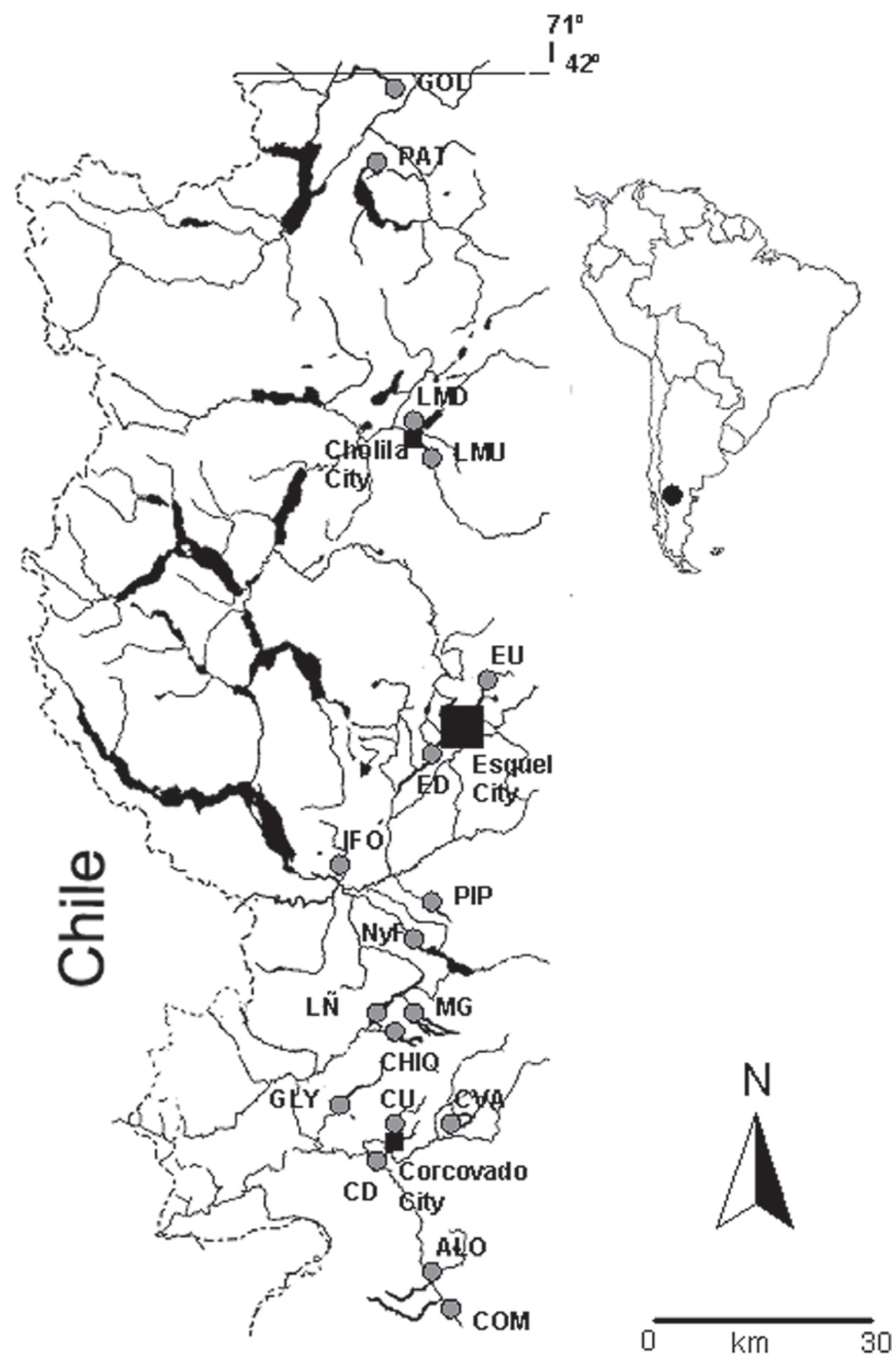

Fig. 1. Map of the study area, and location of the 18 sampling sites distributed in 15 streams of Northwest Patagonia, Argentina.

at $300 \mathrm{~V}$ and a hand net. Stream reaches were blocked off with a downstream net (5 $\mathrm{mm}$ mesh). Each reach was sampled three times; downstream passes of equal effort were done in a slow zigzag pattern. Probably, this sampling technique underestimates the abundance of benthic species such as Hatcheria macraei. However, given that the potential biases associated to the sampling technique might operate with similar intensity in all of the sampling sites, we consider that for the aims of the study (i.e. determining the influence of land uses on stream fish populations) the technique is appropriate. The individuals caught were identified, counted, weighted and measured. Individuals were deposited at the Laboratorio de Investigaciones en Ecología y Sistemática Animal (LIESA), Universidad Nacional de la Patagonia San Juan Bosco. 


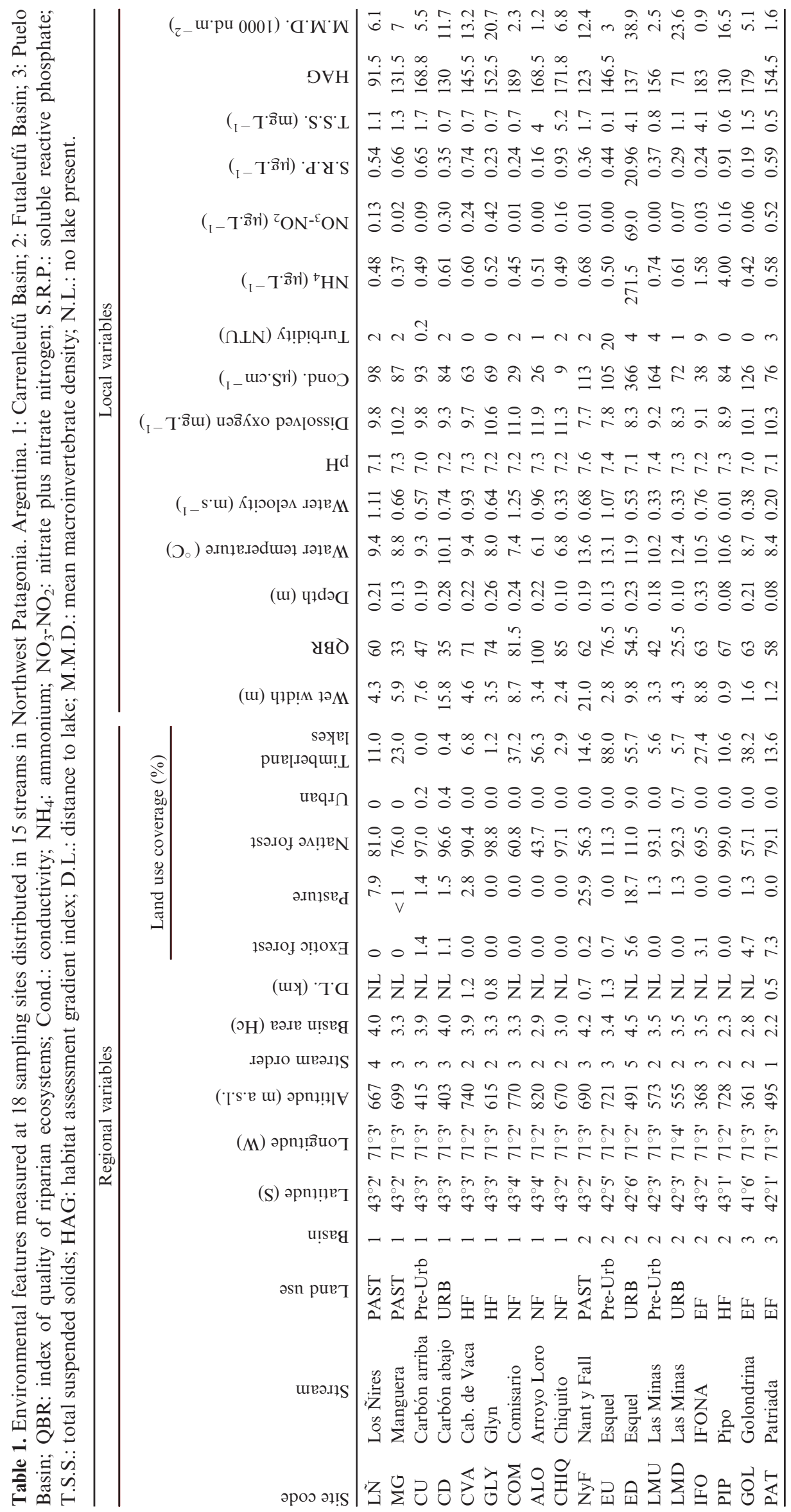




\section{Regional and local variables}

Local and regional environmental variables were determined for each site according to their scale of definition and spatial variability (Table 1). Regional variables included the basin, altitude ( $\mathrm{m}$ above sea level), latitude, longitude, stream order, catchment area (ha) and distance to upstream lakes $(\mathrm{km})$. These variables were obtained from a geographical information system (GIS) (Arc VIEW 3.3 package) and a set of Land Sat images ETM (2000 and 2001) $(15 \mathrm{~m} \times 15 \mathrm{~m}$ resolution) provided by the Dirección Provincial General de Bosques y Parques. The local variables were obtained in situ and included average depth $(\mathrm{m})$, streambed width $(\mathrm{m})$, water velocity $\left(\mathrm{m} . \mathrm{s}^{-1}\right)$, water temperature $\left({ }^{\circ} \mathrm{C}\right)$, dissolved oxygen $\left(\mathrm{mg} . \mathrm{L}^{-1}\right), \mathrm{pH}$, conductivity $\left(\mu \mathrm{S} . \mathrm{cm}^{-1}\right)$, turbidity (NTU), total suspended solids $\left(\mathrm{mg} . \mathrm{L}^{-1}\right)$, nitrate plus nitrite nitrogen $\left(\mu \mathrm{g} . \mathrm{L}^{-1}\right)$, ammonium $\left(\mu \mathrm{g} . \mathrm{L}^{-1}\right)$, soluble reactive phosphate $\left(\mu \mathrm{g} . \mathrm{L}^{-1}\right)$, the index of quality of riparian ecosystems (QBR), the habitat assemblage gradient index (HAG), and macroinvertebrates density. For nutrient analyses water samples were collected below the water surface and kept at $4{ }^{\circ} \mathrm{C}$ and were analyzed following APHA (1994). The QBR was estimated using an adaptation for Patagonian streams (Kutschker et al., 2009). This index combines information on total cover, structure, complexity and naturalness of the riparian vegetation, and the degree of channel alteration. The total QBR score range from 0 to 100; values below 25 indicated extreme degradation whereas values over 90 indicates a good quality of the natural riparian forest. To evaluate the habitat quality we used the HAG following Barbour et al. (1999). This method ranks 10 stream channel features (scored 0 to 20), including epifaunal substrate availability, embeddedness, water velocity and depth, sediment deposition, channel flow, channel modifications, frequency of riffles, condition of banks, bank vegetative protection, and riparian vegetative zone width. The maximum score of 200 points indicates that the river is natural and pristine and in its best possible condition. Both indexes provide an integral view of the factors influencing the biological condition of a stream system. At each study site quantitative benthic macroinvertebrate samples were taken with a Surber sampler (sampling area $=0.09 \mathrm{~m}^{2}$; mesh size $=250 \mu \mathrm{m}$ ). Samples were fixed in situ with $4 \%$ formaldehyde, sorted and identified at the laboratory under at least $5 \times$ magnifications. Then, macroinvertebrate individuals were counted and their density was estimated as individuals per $\mathrm{m}^{2}$.

\section{Data analysis}

To characterize each fish community, the number of individuals $(\mathrm{N})$, density (ind. $\mathrm{m}^{-2}$ ) and biomass $\left(\mathrm{g} . \mathrm{m}^{-2}\right)$ of species were calculated. Differences in regional and local environmental variables were tested using Kruskall-Wallis and Duncan post hoc test (Sokal and Rohlf, 1995).
To determine the degree of similitude among fish communities, a cluster analysis was performed. Clustering was calculated with complete linkage and the Spearman correlation (dissimilarity) was employed. Prior to the analysis, and in order to increase normality, data were appropriately transformed $(\log x+1)$.

To assess relationships between fish assemblages and environmental variables, a canonical correspondence analysis (CCA) was performed using CANOCO (ter Braak, 1986). Total fish species densities were $\log (x+1)$ to minimise the effect of extreme values. Separate CCAs were performed using local and regional environmental data sets. Variables that were strongly intercorrelated with others (those with an inflation factor $>10$ ) in the initial analysis, were removed. A forward stepwise selection procedure was used to obtain the best predictors for the models including a set of independent variables for each one. The model was tested using a Monte Carlo permutation test (999 permutations) at a significance level of 0.05 . Simple-linear regression analyses $(p<0.05)$ were plotted to explore relationships between fish density and biomass, with environmental variables.

\section{Results}

\section{Stream features}

Sites were located between $361 \mathrm{~m}$ a.s.1. (GOL, Table 1) and $820 \mathrm{~m}$ a.s.1. (ALO). Stream orders ranged from 1 (PAT) to 5 (ED) and streambed wet width ranged from $0.9 \mathrm{~m}$ (PIP) to $21 \mathrm{~m}(\mathrm{NyF})$. Water velocity was comprised between $0.01 \mathrm{~m} . \mathrm{s}^{-1}$ (PIP) and $1.25 \mathrm{~m} . \mathrm{s}^{-1}$ (COM). The lowest and highest dissolved oxygen contents were observed at $\mathrm{NyF}\left(7.7 \mathrm{mg} . \mathrm{L}^{-1}\right)$ and ALO (11.9 mg.L $\left.{ }^{-1}\right)$ respectively. According to the HAG and QBR indices, LMD (urban site) had the lowest scores and, in general, native forest sites showed the best riparian and habitat conditions (Table 1). ED was the most affected urban site and, as expected, presented the highest values of nutrients $\left(\mathrm{NH}_{4}, \mathrm{NO}_{3}-\mathrm{NO}_{2}, \mathrm{SRP}\right)$ and water conductivity (Table 1).

The highest macroinvertebrate density was observed in the urban sites ED (38348 ind. $^{-2}$ ) and LMD (23 619 ind. $\mathrm{m}^{-2}$ ), whereas the lowest density was observed at IFO (932 ind. ${ }^{-2}$ ) (exotic forest) (Table 1). At most sites, the benthic macroinvertebrate community was dominated by aquatic insects. However, the importance of Orthocladinae species (Chironomidae), Hyalella araucana (Amphipoda), Lumbriculus variegatus, Limnodrilus spp. (Oligochaeta), and Glossiphonidae (Hirudinea), increased in urban sites.

\section{Land use and environmental features}

There were significant differences in environmental variables among land uses, independently of the spatial scale (regional/local). Native forest sites showed the highest QBR and HAG values (Kruskall-Wallis, $p<0.05$ ). 
Table 2. Number (N), density (ind. $\mathrm{m}^{-2}$ ) and biomass (g.m $\mathrm{m}^{-2}$ ) of fish at the various sampling sites at Northwest Patagonia, Argentina. (E): Exotic species, (N): native species.

\begin{tabular}{|c|c|c|c|}
\hline Site & $\mathrm{N}$ & $\begin{array}{c}\text { Density } \\
{\text { (ind. } \mathrm{m}^{-2} \text { ) }}\end{array}$ & $\begin{array}{l}\text { Biomass } \\
\left(\text { g.m }{ }^{-2}\right)\end{array}$ \\
\hline \multicolumn{4}{|l|}{ Los Nires } \\
\hline O. mykiss $(\mathrm{E})$ & 56 & 1.67 & 2.77 \\
\hline H. macraei $(\mathrm{N})$ & 1 & 0.009 & 0.01 \\
\hline \multicolumn{4}{|l|}{ Manguera } \\
\hline O. mykiss $(\mathrm{E})$ & 24 & 0.36 & 0.70 \\
\hline H. macraei $(\mathrm{N})$ & 4 & 0.18 & 0.37 \\
\hline \multicolumn{4}{|l|}{ Carbón arriba } \\
\hline O. mykiss (E) & 67 & 1.53 & 1.87 \\
\hline S. $\operatorname{trutta}(\mathrm{E})$ & 34 & 1.29 & 1.88 \\
\hline \multicolumn{4}{|l|}{ Carbón abajo } \\
\hline O. mykiss (E) & 25 & 1.57 & 2.79 \\
\hline S. trutta $(\mathrm{E})$ & 27 & 0.30 & 2.57 \\
\hline \multicolumn{4}{|l|}{ Cabeza de Vaca } \\
\hline O. mykiss $(\mathrm{E})$ & 30 & 2.16 & 4.32 \\
\hline H. macraei $(\mathrm{N})$ & 1 & 0.44 & 1.10 \\
\hline \multicolumn{4}{|l|}{ Glyn } \\
\hline O. mykiss (E) & 67 & 1.05 & 1.57 \\
\hline S. trutta $(\mathrm{E})$ & 53 & 0.99 & 1.53 \\
\hline H. macraei $(\mathrm{N})$ & 1 & 0.17 & 0.35 \\
\hline \multicolumn{4}{|l|}{ Comisario } \\
\hline O. mykiss (E) & 60 & 1.32 & 2.14 \\
\hline Arroyo Loro & - & - & - \\
\hline \multicolumn{4}{|l|}{ Chiquito } \\
\hline O. mykiss (E) & 51 & 1.66 & 2.72 \\
\hline \multicolumn{4}{|l|}{ Nant y Fall } \\
\hline O. mykiss $(\mathrm{E})$ & 76 & 0.28 & 0.44 \\
\hline H. macraei $(\mathrm{N})$ & 3 & 0.09 & 0.16 \\
\hline O. hatcheri $(\mathrm{N})$ & 2 & 0.07 & 0.10 \\
\hline \multicolumn{4}{|l|}{ Esquel EU } \\
\hline O. mykiss (E) & 13 & 0.82 & 2.10 \\
\hline S. trutta $(\mathrm{E})$ & 2 & 0.34 & 1.34 \\
\hline \multicolumn{4}{|l|}{ Esquel ED } \\
\hline O. mykiss (E) & 34 & 0.53 & 1.43 \\
\hline \multicolumn{4}{|l|}{ Las Minas LMU } \\
\hline O. mykiss (E) & 131 & 4.35 & 5.68 \\
\hline \multicolumn{4}{|l|}{ Las Minas LMD } \\
\hline O. mykiss (E) & 283 & 2.28 & 1.73 \\
\hline \multicolumn{4}{|l|}{ IFONA } \\
\hline O. mykiss (E) & 15 & 0.39 & 0.61 \\
\hline S. trutta $(\mathrm{E})$ & 7 & 0.29 & 0.76 \\
\hline Pipo & - & - & - \\
\hline Golondrina & - & - & - \\
\hline \multicolumn{4}{|l|}{ Patriada } \\
\hline S. fontinalis (E) & 15 & 0.28 & 8.37 \\
\hline
\end{tabular}

Urban sites presented the lowest values of QBR and pasture sites the lowest values of HAG (Table 1). The conductivity varied according to the land use (Kruskall-Wallis, $p<0.05$ ); pre-urban sites presented the highest values whereas native forest sites showed the lowest ones (Table 1). The benthic macroinvertebrate density also varied according to the land use (KruskallWallis, $p<0.05$ ); urban and exotic forest sites presented the highest and lowest densities respectively. Native forest sites had significantly lower water temperature than pasture and urban sites (Kruskall-Wallis, $p<0.01$ ).

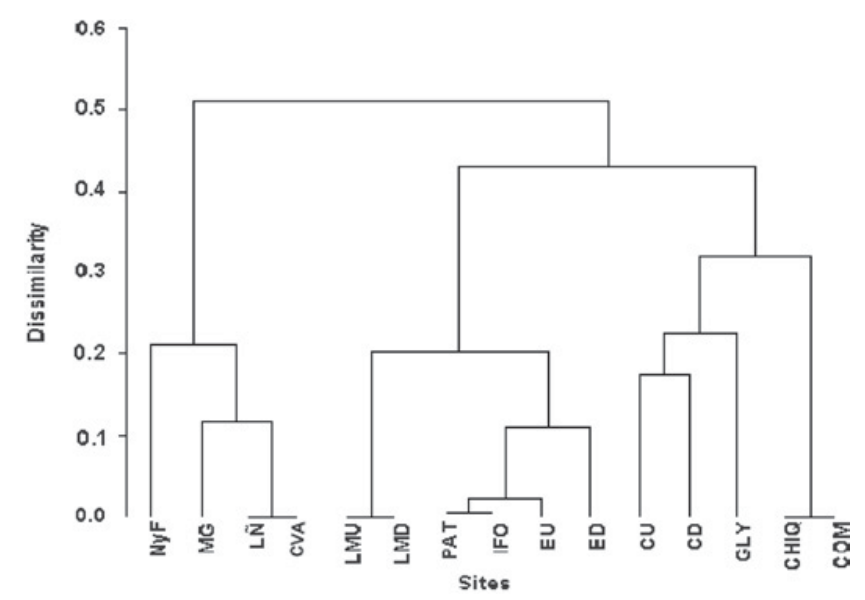

Fig. 2. Clustering produced by the Spearman dissimilarity analysis with strong link calculated from data on fish density at the 18 sampling sites. Those streams where fish were absent from the samples (GOL, PIP and ALO) were not included in the analysis.

Most chemical variables including $\mathrm{NO}_{3}-\mathrm{NO}_{2}, \mathrm{NH}_{4}$ and SRP (see Table 1), showed higher mean values at urban sites than at other sites. However, chemical variables showed high fluctuations, possibly explained by extreme values at ED urban site.

\section{Fish species distribution and abundance}

A total of 1082 fish individuals belonging to five species were caught. Individuals belonging to exotic species largely predominated in the samples $(98.9 \%$ of the individuals sampled) whereas native fish were scarcely represented. Oncorhynchus mykiss exhibited the widest distribution and was the most abundant fish (87.67 ind. $\mathrm{m}^{-2}$ ), followed by $S$. trutta $\left(9.12\right.$ ind. $\mathrm{m}^{-2}$ ) and $S$. fontinalis $\left(2.74\right.$ ind $\left.\mathrm{m}^{-2}\right)$. The native $H$. macraei and $O$. hatcheri were the less abundant fish in the samples $(0.44$ and 0.03 ind $\mathrm{m}^{-2}$ respectively). A similar pattern was observed in the biomass contribution of the different species: O. mykiss (88.78 g.m $\left.{ }^{-2}\right)$, S. trutta $\left(5.53\right.$ g.m $\left.{ }^{-2}\right)$, S. fontinalis $\left(5.57\right.$ g.m $\left.{ }^{-2}\right)$, H. macraei $\left(0.12\right.$ g.m $\left.{ }^{-2}\right)$, and O. hatcheri $\left(<0.01 \mathrm{~g} . \mathrm{m}^{-2}\right)$.

The maximum fish species richness (three species) was observed at GLY and NyF, whereas no fish were caught at ALO, PIP and GOL. The highest density of individuals was observed at LMU (pre-urban site, 4.34 ind. $^{-2}$ ) (Table 2).

The clustering of sites based on fish species density is presented in Figure 2. The first group included sites located in the ecotone between the Andes and the steppe (NyF, MG, LN and CVA) where the native H. macraei was present. The second group was represented by sites dominated by exotic species. Thus, LMU and LMD (preurban and urban sites respectively) showed high similarity, as well as CHIQ and COM (native forest). 


\section{Multivariable response of fish communities}

The CCA based on regional variables (Fig. 3A) revealed a strong species separation along the two canonical axes $(\lambda 1=0.95 ; \lambda 2=0.29)$. The exploratory variables accounted for $58.6 \%$ of the total variation in site-assemblage composition, with the first and second axes displaying $76.3 \%$ of the variation. The first axis revealed a clear separation among fish assemblages mostly evidenced between $S$. fontinalis (positive $\mathrm{X}$ axis) and those assemblages dominated by S. trutta and by O. mykiss, $O$. hatcheri and $H$. macraei (negative values on $\mathrm{X}$ axis). This gradient was associated with the exotic forest land use and catchment area. The second CCA axis, although with less explanatory power, showed that altitude influenced fish species assemblages (Table 3).

The first two axes in the CCA ordination based on local variables (Fig. 3B) were significant $(p<0.05)$, with eigenvalues of 0.62 and 0.06 respectively. The explanatory variables accounted for $38.8 \%$ of the total variation in assemblage composition, with the first and second axes displaying $42.8 \%$ of the variation. As depicted in the biplot, the first axis revealed a clear separation among of fish assemblages mostly evidenced between $S$. fontinalis (positive $\mathrm{X}$ axis) and those fish assemblages dominated by $S$. trutta and by $O$. mykiss, O. hatcheri and $H$. macraei (negative values on $\mathrm{X}$ axis). Axis showed a clear separation of fish assemblages mainly explained by water velocity and mean macroinvertebrate density. The HAG index and the total suspended solids defined the CCA 2 gradient. However, according to the Monte Carlo test only CCA 1 was statistically significant (Table 3).

Simple-linear regression analyses showed that the fish biomass $(\mathrm{r}=0.34, p<0.05)$ (Fig. 4A) and density $(\mathrm{r}=0.21$, $p<0.05$ ) (Fig. 4B) were significantly related to native forest coverage. On the other hand, a subset of independent environmental variables was used in stepwise multiple regression analyses, but none were statistically significant.

\section{Discussion}

This is the first attempt to link the effects of different land use on fish communities in low order streams in northwest Patagonia, Argentina. In this study we documented changes in physical (e.g. temperature), chemical (i.e. conductivity), and environmental variables (i.e. QBR, HAG) associated with different land-use practices. Moreover, we detected significant shifts in fish assemblages in the sampled sites and this is consistent with those shifts reported recently by Lara et al. (2009) for Chilean streams. Land use practices have also been proved to modify other biological communities, for example macroinvertebrates (Miserendino and Masi, 2010). Nevertheless, we recognize that it was difficult to distinguish clearly between the effects of natural and anthropogenic disturbances on fish. We believe that the features of native fish fauna, the practice of stocking trout and, in addition, the interactive effects between the fauna (native and
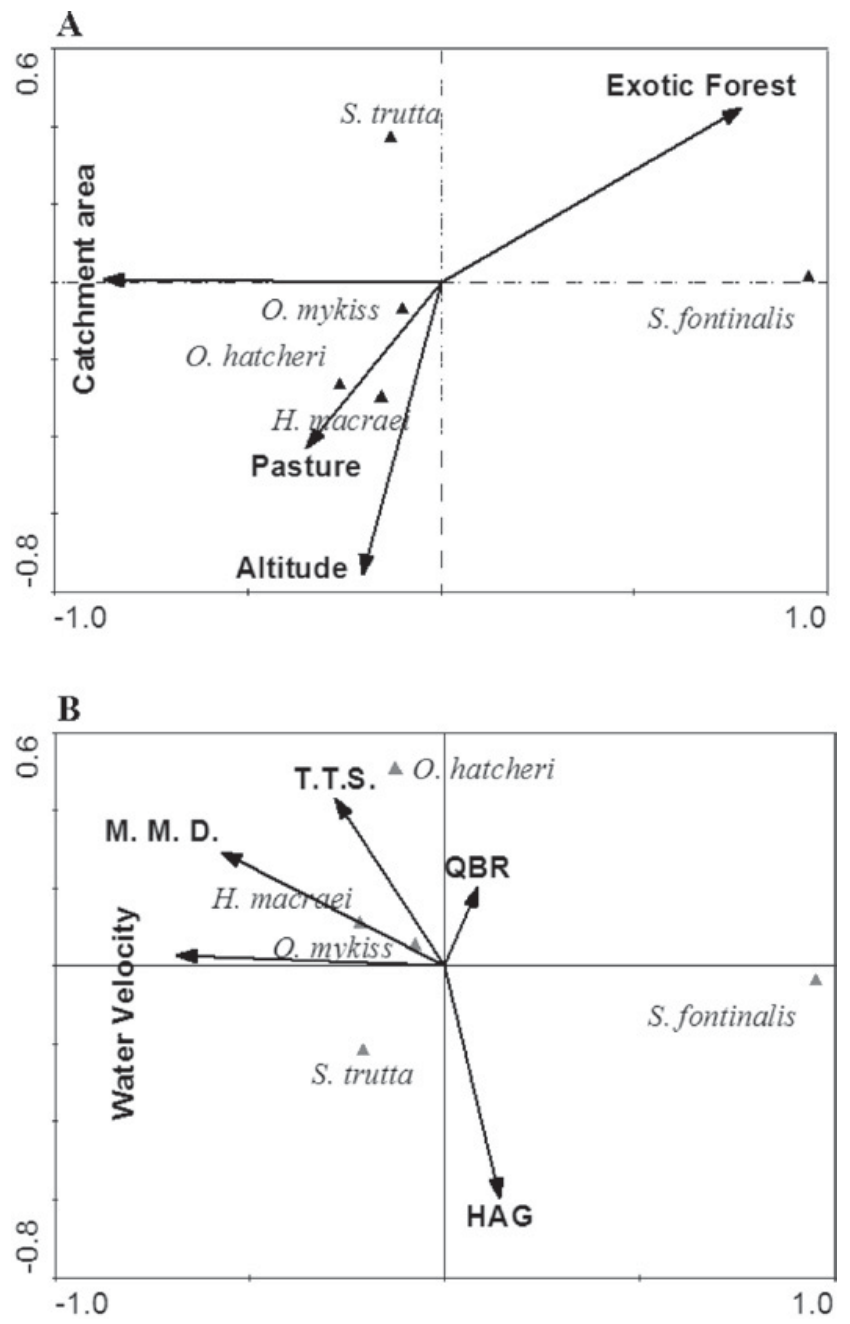

Fig. 3. Axes one and two of the canonical correspondence analysis biplot for the fish species represented in the samples. (A): Regional variables, (B): local variables.

exotic) and the environmental regional and local factors make it difficult to interpret of observed patterns.

In agreement with previous reports for Patagonia (Ringuelet, 1975; Pascual et al., 2002), the fish species richness recorded in this study was low. It is well known that the Patagonian fish fauna richness is lower than that observed in other cold-temperate regions of the southern hemisphere (Baigún and Ferriz, 2003). The exotic $O$. mykiss was the most abundant fish in the sites studied (both density and biomass). This is, at least, partially explained by the fact that $73.3 \%$ of the individuals stocked in the study area belong to this species (Dirección de Pesca Continental de Chubut, unpublished data). On the contrary, native species were largely less abundant than salmonids and they were absent from most sampled sites. The sites where H. macrae $i$ was represented in fish samples were coincident with those where this fish was present in Surber samples. This evidences that, although the fish sampling technique might have underestimated the abundance of H. macraei (see Material and methods), its distribution pattern was well reflected by the 
Table 3. Intraset correlation of environmental variables with the axes of CCA based on local and regional environmental data sets. Biomass of the fish species sampled $(n=5)$ in 18 sampling sites (see Table 1) in March 2006.

\begin{tabular}{|c|c|c|c|c|c|}
\hline Regional variable & Axis 1 & Axis 2 & Local variable & Axis 1 & Axis 2 \\
\hline Altitude & -0.20 & -0.75 & QBR & 0.08 & 0.20 \\
\hline Catchment area & -0.87 & 0.004 & Water velocity & -0.69 & 0.02 \\
\hline Exotic forest & -0.77 & 0.44 & TSS & -0.28 & 0.43 \\
\hline \multirow[t]{2}{*}{ Pasture } & -0.34 & -0.42 & $\mathrm{HAG}$ & 0.14 & -0.59 \\
\hline & & & M.M.D. & -0.57 & 0.29 \\
\hline Eigenvalues & 0.95 & 0.29 & & 0.63 & 0.07 \\
\hline Species-environment correlations & 0.97 & 0.91 & & 0.80 & 0.43 \\
\hline Cumulative percentage variance of species data & 58.6 & 76.3 & & 38.8 & 95.9 \\
\hline
\end{tabular}

$P$-values for Monte Carlo permutation test

Axis $1: \mathrm{F}=14.1, p<0.01$

Axis $1: \mathrm{F}=5.70, p<0.02$

All canonical axes: $\mathrm{F}=5, p<0.002$

sampling protocol. A pattern of fish abundance and distribution similar to the one observed here was reported by Soto et al. (2006) for Chilean Patagonian streams, evidencing the successful expansion of the salmonids in Patagonia. Moyle and Light (1996) reported that the hydrological regime in California streams and estuaries is one of the most important variables explaining fish assemblages. These authors also proposed that in aquatic systems with high levels of human disturbance, a much wider range of species can invade than in systems with low levels of human disturbances. Considering the patterns of fish distribution observed in this study, our results fully support such predictions. However, we also consider that in the study area the successful invasion of exotic species is strongly supported by a continuous stocking.

Several studies showed that stream physical, chemical, geographical, environmental and biological characteristics strongly determine the structure of fish assemblages (Lancaster et al., 1990; Moyle and Light, 1996; Taylor and Warren, 2001). Jowett et al. (1996) and Williams et al. (2003) reported for New Zealand and USA respectively that the variation in fish densities observed in different streams was explained by differences in the environmental variables at a basin-level. Similarly, Moyle et al. (2003) observed a strong association between fish densities and the strategies of fish stock management in the Cosumnes River basin (USA), whereas Menni et al. (2005) reported that environmental constraints overruled fish assemblages in Northwest Argentina. Our results revealed that, at a regional scale, the fish assemblages were primarily determined by watershed features like altitude and catchment area, and the land use effects (exotic forest and pasture). Assemblage composition was also related to some localscale features such as water velocity, food availability (density of benthic macroinvertebrates), instream characteristic and riparian features.

Jowett and Richardson (2003) reported a positive and significant correlation between streambed wet widths, altitude and fish density for New Zealand streams. This could be related with the fact that bigger streams offer higher habitat diversity, which in turn results in a greater availability of refuges, feeding places and spawning areas. In our study, NyF and GLY were the sites where three fish species coexisted. Compared with the remaining sites, $\mathrm{NyF}$
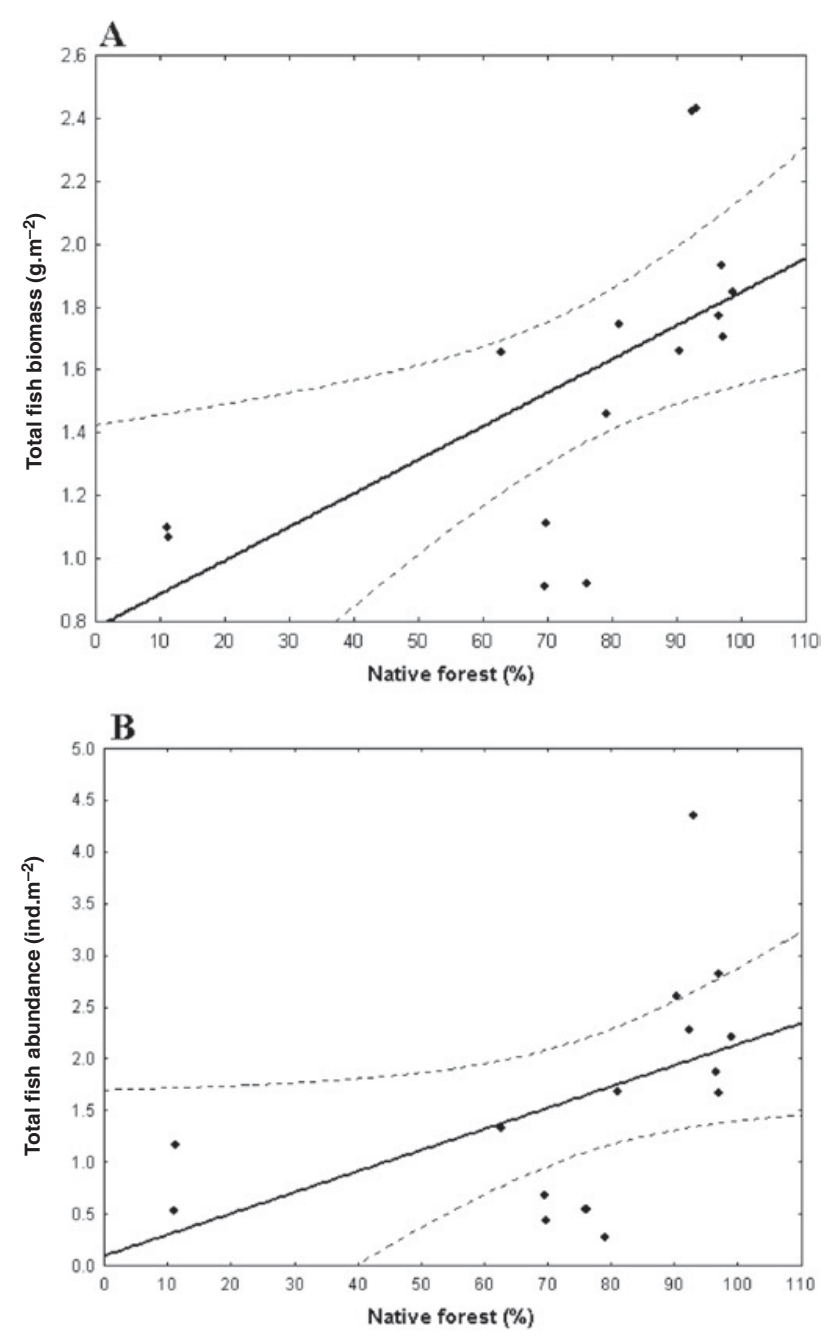

Fig. 4. Total fish biomass (A) and density (B) as a function of native forest coverage $(\%)$ at a basin scale.

and GLY show a great variety of habitats such as patches of macrophytes, backwaters, edges, shadow pools, runs and riffles which resulted in high HAG values, plus higher macroinvertebrate abundances. These characteristics make both sites highly suitable in terms of environmental heterogeneity which, together with habitat quality, is positively correlated with fish diversity (Ward, 1989; 
Barbour et al., 1999; Allan, 2004). It is well known that several human activities (e.g. changes in land use, clear cutting of riparian vegetation, urban settlements, etc.) can affect the characteristics of streams and consequently can modify the fish assemblages, usually negatively affecting the native fish populations (Aparicio et al., 2000). Whilst in our study the most altered sites (urban sites) support solely exotic fish, native species were only present in sites with low to moderate perturbation (pasture sites), although they occurred with lower densities than exotic species at the same sites. This is consistent with reports for New Zealand, where pasture streams present the highest densities of native fish species (Rowe et al., 1999; among others).

Paul and Meyer (2001) indicated that salmonids present a high capacity to occupy and compete in altered environments. These authors also pointed out that, compared with forested streams, salmonids grow faster and to larger sizes in urban streams, increasing the fish production up to three times, presumably as a result of warmer temperatures and greater invertebrate biomass. In our study urban sites were the most altered sampling sites (as reflected by the QBR and HAG indexes) presented higher water temperatures and macroinvertebrate biomass, and, consequently, O. mykiss was the dominant species. However, and despite the relatively lower food availability, the densities of $O$. mykiss were higher in pre-urban than in urban sites (Mann-Whitney U-test, $p<0.05)$. Thus, although $O$. mykiss is able to occupy altered stream, its populations seem are negatively affected by urban activities.

Several studies carried out in Argentina reported some trophic, reproductive and habitat segregation between native and exotic species (see review in Pascual et al., 2007). Interestingly, a geographic segregation was observed in Chile, native fish being abundant in central valleys and depressions and practically absent in Andean streams where introduced fish species were abundant (Soto et al., 2006). In our study, the native species were restricted only to five high altitude sites located in the ecotone region between the Andes and the steppe where salmonids were also present. However, native fish were absent from Andean sites where introduced species were present and abundant. This scenario resembles the one reported by Soto et al. (2006), suggesting that the same processes related to the interaction between native and introduced species might be operating at both sides of the Andes. However, sampling sites located in the ecotone region were affected by two of the less adverse land uses for native fish populations (pasture and native forest), whereas most of the Andean sites were associated to more disturbing land uses (urban settlements and exotic forest). Thus, both processes (changes in land uses and competition between native and exotic fish) seem to be interacting and more studies are required to better understand their real effects on fish communities.

Despite the evidence indicating that some of the stream variables considered in the study significantly determined the structure of the fish assemblages, our results also suggest that additional factors should be considered to better understand the current patterns of fish distribution in the study area. It is well known that introduced species influence freshwaters systems at the individual, population, community, and ecosystem levels (Moyle et al., 2003; Penaluna et al., 2009). At a population level, several authors reported that salmonids are among the main predators and food/habitat competitors of native fish, thus strongly influencing the structure of their populations and their patterns of distribution (Cussac et al., 1997; Macchi et al., 2005; Penaluna et al., 2009). Although the native fish species described for the study area are still present there (Lattuca et al., 2007), circumstantial evidence suggest that their abundances and ranges of distribution steadily decreased in parallel with the expansion of salmonids. The management of salmonid populations in the study area is characterised by the absence of rational stock assessments and by the continuous supplementation of wild populations with hatchery fish. The unique objective of this practice is to maintain the stocks of salmonids to satisfy the increasing recreational fishing demands, and the ecological consequences of this strategy are not considered. As a consequence, native fish populations are forced to a permanent re-adaptation to changing and unpredictable conditions and to cope with large populations of introduced competitors/predators. If this practice is sustained, stream fish assemblages will continuously change in an unpredictable way, and native fish populations will become increasingly rare and restricted in their distributions.

Acknowledgements. This paper was supported by the PADI Foundation (Grant 19/2006) and CONICET (PIP 5733). The authors wish thank to Dr. George Pess (Federal, NOAA Fisheries - USA) and the two anonymous reviewers for thoughtful review and valuable comments on the manuscript. We also thank to Estancia Tecka for the electro fishing equipment provided and the staffs of estancias Los Nires and Río Frío and Mr. Cirilo Nancual who facilitate the access to some of the sampling sites. Dr. M. Archangelsky and C. Brand for fieldtrip assistance. This is the contribution to the Laboratorio de Investigaciones en Ecología y Sistemática Animal (LIESA) N ${ }^{\circ} 59$.

\section{References}

Allan J.D., 1995. Modification of running waters by humankind. In: Chapman \& Hall (eds.), Stream Ecology: structure and function of running water, London.

Allan J.D., 2004. Landscapes and riverscapes: the influence of land use on stream ecosystems. Annu. Rev. Ecol. Evol. Syst., 35, 257-284.

Aparicio E., Vargas M.J., Olmo J.M. and de Sosota A., 2000. Decline of native freshwater fishes in a Mediterranean watershed on the Iberian peninsula: A quantitative assessment. Environ. Biol. Fish., 59, 11-19.

APHA, 1994. Standard Methods for the Examination of Water and Wastewater, American Public Health Association, Hanover. 
Arismendi I., Soto D., Penaluna B., Jara C., Leal C. and León Muñóz J., 2009. Aquaculture non-native salmonids invasions and associated declined of native fishes in Northern Patagonian lakes. Freshwat. Biol., 54, 1135-1147.

Baigún C. and Ferriz R.A., 2003. Distribution patterns of freshwater fishes in Patagonia (Argentina). Org. Divers. Evol., 3, 151-159.

Barbour M.T., Gerritsen J., Snyder B.D. and Stribling J.B., 1999. Rapid Bioassessment Protocols for Use in Streams and Wadeable Rivers: Periphyton, Benthic Macroinvertebrates and Fish, 2nd edition, EPA, U.S. Environmental Protection Agency, Washington, D.C.

Boët P., Duvoux B., Allardi J. and Belliard J., 1994. Incidence des orages estivaux sur les peuplements piscicoles de la Seine à l'aval de l'agglomération parisienne (bief AndrésyMéricourt). La Houille Blanche, 1-2, 141-147.

Coronato F.R. and del Valle H.F., 1988. Caracterización hídrica de las cuencas hidrográficas de la provincia del Chubut. Publicación Técnica, Cenpat-Conicet, Puerto Madryn, Chubut.

Cussac V.E., Battini M.A., Macchi P.J. and Alonso M., 1997. Patagonian fishes: life and management in lakes and reservoirs. Resúmenes VII Conferencia Internacional sobre Conservación y Gestión de Lagos, San Martín de los Andes, Neuquén.

Di Prinzio C.Y. and Pascual M.A., 2008. The establishment of exotic Chinook salmon (Oncorhynchus tshawytscha) in Pacific rivers of Chubut, Patagonia, Argentina. Ann. Limnol. - Int. J. Lim., 44, 25-32.

Ferreira M.T., Sousa L., Santos J.M., Reino L., Oliveira J., Almeida P.R. and Cortes R.V., 2007. Regional and local environmental correlates of native Iberian fish fauna. Ecol. Freshw. Fish, 16, 504-514.

Gerhard P., Moraes R. and Molander S., 2004. Stream fish communities and their associations to habitat variables in a rain forest reserve in southeastern Brazil. Environ. Biol. Fish., 71, 321-340.

Heartsill-Scalley T. and Aide T.M., 2003. Riparian vegetation and stream condition in a tropical agriculture-secondary forest mosaic. Ecol. Appl., 13, 225-234.

Higgins C.L. and Strauss R.E., 2008. Modeling stream fish assemblages with niche apportionment models: patterns, processes, and scale dependence. Trans. Am. Fish. Soc., 137, 696-706.

Hoeinghaus D.J., Winemiller K.O. and Birnbaum J.S., 2006. Local and regional determinants of stream fish assemblage structure: inferences based on taxonomic vs. functional groups. J. Biogeogr., 34, 324-338.

Jowett I.G. and Richardson J., 2003. Fish communities in New Zealand rivers and their relationship to environmental variables. New Zeal. J. Mar. Fresh., 37, 347-366.

Jowett I., Richardson J. and McDowall R., 1996. Relative effects of in-stream habitat and land use of fish distribution and abundance in tributaries of the Grey River, New Zealand. New Zeal. J. Mar. Fresh., 30, 463-475.

Kolar C.S. and Lodge D.M., 2000. Freshwater Nonindigenous Species: Interactions with other Global Changes. In: Moonley H.A. and Hobbs R.J. (eds.), Invasive Species in a Changing World, Island Press, Washington D.C., 3-30.

Kutschker A.M., Brand C. and Miserendino M.L., 2009. Evaluación de la calidad de los bosques de ribera en ríos del
NO del Chubut sometidos a distintos usos de la tierra. Ecología Austral, 19, 19-34.

Lancaster J., Hildrew A.G. and Townsend C.R., 1990. Stream flow and predation effects on the spatial dynamicas of benthic invertebrates. Hydrobiologia, 203, 177-190.

Lara A., Little C., Urrutia R., McPhee J., Álvarez-Garretón C., Oyarzún C., Soto D., Donoso P., Nahuelhual L., Pino M. and Arismendi I., 2009. Assessment of ecosystem services as an opportunity for the conservation and management of native forests in Chile. Forest Ecol. Manag., 258, 415-424.

Lattuca M.E., Ortubay S., Battini M.A., Barriga J.P. and Cussac V.E., 2007. Presumptive environmental effects on body shape of Aplochiton zebra (Pisces, Galaxiidae) in northern Patagonian lakes. J. Appl. Ichthyol., 23, 25-33.

Lorion C.M. and Kennedy B.P., 2009. Riparian forest buffers mitigate the effects of deforestation on fish assemblages in tropical headwater streams. Ecol. Appl., 19, 468-479.

Macchi P.J., Vigliano P.H., Pascual M.A., Alonso M.F., Denegri M.A., Milano D., García Asorey D.M. and Lippolt G.E., 2005. Historical policy goals for fish management in Northern Continental Patagonia, Argentina: a structuring force of actual fish assemblages? In: Nielsen J., Dodson J., Friedland K., Hamon T., Hughes N., Musick J. and Verspoor E. (eds.), Proceedings of the Fourth World Fisheries Congress 2004 on reconciling fisheries with conservation: the challenge of managing aquatic ecosystem, American Fisheries Society, Symposium, Bethesda.

Magalhães M.F., Batalha D.C. and Collares-Pereira M.J., 2002. Gradients in stream fish assemblages across a Mediterranean landscape: contributions of environmental factors and spatial structure. Freshwat. Biol., 47, 1015-1031.

McDowall R.M., 2003. Impact of introduced salmonids on native galaxiids in New Zealand upland stream: a new look at an old problem. Trans. Am. Fish. Soc., 132, 229-238.

Menni R.C., Miquelarena A.M. and Volpedo A.V., 2005. Fishes and environment in northwestern Argentina: from lowland to Puna. Hydrobiologia, 544, 33-49.

Miserendino M.L. and Masi C., 2010. The effects of land use on environmental features and functional organization of macroinvertebrate communities in Patagonian low order streams. Ecol. Indic., 10, 311-319.

Moyle P.B. and Light T., 1996. Biological invasions of fresh water: empirical rules and assembly theory. Biol. Cons., 78, 149-161.

Moyle P., Crain K., Whitener K. and Mount J.F., 2003. Alien fishes in natural streams: fish distribution, assemblages structure, and conservation in the Cosumnes River, California, U.S.A. Environ. Biol. Fish., 68, 143-162.

Ortubay S. and Cussac V., 2000. Threatened fishes o the world: Gymnocharacinus bergi Steindachner, 1903 (Characidea). Environ. Biol. Fish., 58, 144.

Pascual M., Macchi P., Urbanski J., Marcos F., Riva Rossi C., Novara M. and Dell'Arciprete P., 2002. Evaluating potential effects of exotic freshwater fish from incomplete species presence-absence data. Biol. Inv., 4, 101-113.

Pascual M.A., Cussac V., Dyer B., Soto D., Vigliano P., Ortubay S. and Macchi P., 2007. Freshwater fishes of Patagonia in the 21 st century after a hundred years of human settlement, species introductions, and environmental change. AEHM, $10,2,212-227$. 
Paul M.J. and Meyer J.L., 2001. Streams in the urban landscape. Annu. Rev. Ecol. Evol. Syst., 3, 333-365.

Penaluna B., Arimsendi I. and Soto D., 2009. Evidence of interactive segregation between introduced trout and native fishes in Northern Patagonian Rivers, Chile. Trans. Am. Fish. Soc., 138, 839-845.

Pesce S.F. and Wunderlin D.A., 2000. Use of water quality index to verify the impact of Córdoba city (Argentina) on Suquía River. Water Res., 3, 2915-2926.

Poff N.L., 1997. Landscape filters and species traits: towards mechanistic understanding and prediction in stream ecology. J. N. Amer. Benthol. Soc., 1, 391-409.

Porter M., Rosenfeld R. and Parkinson E.A., 2000. Predictive models of fish species distribution in the Blackwater drainage, British Columbia. N. Am. J. Fish. Manag., 20, 349-359.

Ringuelet R., 1975. Zoogeografía y ecología de los peces de aguas continentales de la Argentina y consideraciones sobre las áreas ictiológicas de América del Sur. Ecosur, 2, 1-122.

Rowe D.K., Chisnall B.L., Dean T.L. and Richardson J., 1999. Effects of land use on native fish communities in east coast streams of the North Island of New Zealand. New Zeal. J. Mar. Fresh., 3, 141-151.

Rowe D.K., Smith J., Quinn J. and Boothroyd I., 2002. Effects of logging with and without riparian strips on fish species abundance, mean size, and the structure of native fish assemblages in Coromandel, New Zealand Streams. New Zeal. J. Mar. Fresh., 36, 67-79.

Sokal R.R. and Rohlf F.J., 1995. Biometry, 3rd edition, W.H. Freeman and Company, New York.

Soto D., Arismendi I., Gonzalez J., Sanzana J., Jara F., Jara C., Guzman E. and Lara A., 2006. Southern Chile, trout and salmon country: invasion patterns and threats for native species. Rev. Chil. Hist. Nat., 79, 97-117.

Taylor C.M. and Warren M.L., 2001. Dynamics in species composition of stream fish assemblages: Environmental variability and nested subsets. Ecology, 82, 2320-2330.

ter Braak C.J.F., 1986. Canonical correspondence analysis: a new eigenvector technique for multivariate direct gradient analysis. Ecology, 67, 1167-1179.

Wallace J.B., Eggert S.L. and Meyer J.L., 1997. Multiple trophic levels of a forest stream linked to terrestrial litter inputs. Science, 277, 102-104.

Ward J.V., 1989. The four dimensional nature of lotic ecosystems. J. N. Amer. Benthol. Soc., 8, 2-8.

Williams L.R., Taylor C.M., Warren M.L. Jr. and Clingenpeel A., 2003. Environmental variability, historical contingency, and the structure of regional fish and macroinvertebrate faunas in Ouachita Mountain stream systems. Environ. Biol. Fish., 67, 203-216. 